\title{
Heat and death
}

Times were strange on the planet at the beginning of the Triassic period, around 250 million years ago. Earth had just come through the end-Permian mass extinction event that wiped out the vast majority of species. Then, for reasons that have remained unclear, life remained sparse for millions of years, and the situation grew even worse. A new study suggests that a particularly mysterious interval at the end of the recovery period, called the endSmithian crisis, was probably the result of an unprecedented and sweltering round of global warming.

Blame for the end-Permian extinction event is commonly placed on carbondioxide-belching volcanic activity in Siberia. There was some greenhouse warming tied to the event, but the elimination of species was associated more with problems such as loss of oxygen in the oceans and ozone depletion in the upper atmosphere leading to increases in damaging ultraviolet rays.

But even though the literal and figurative dust settled at the beginning of the Triassic period, recovery was slow for millions of years. Coal bed records suggest there was very little plant life, and those few species that were around were generally small - a phenomenon dubbed the Lilliput effect. Then the small plants, too, began passing into oblivion.
A multinational team led by Yadong Sun at the China University of Geosciences in Wuhan set out to study how temperatures evolved over this time frame (Science 338, 366-370; 2012). The researchers focused on prehistoric eel-like marine animals called conodonts (pictured), or, more specifically, their teeth: conodont teeth are well preserved in fossil records such as those in south China.

When marine animals grow hard parts such as teeth, the ratio between the various oxygen isotopes alters in response to ocean temperature changes. So measuring isotope ratios is a well-established method for estimating ocean temperatures.

Analysing thousands of teeth, the team showed that equatorial ocean temperatures rose dramatically after the end-Permian event, hitting levels of around $40{ }^{\circ} \mathrm{C}$ or more, both within the water column and at the surface. Water temperatures at that level would probably kill all but the hardiest marine species. The situation on land would have been similar, which could account for the absence of plant material and hence coal bed formation. The team also showed that fish were all but non-existent during the Smithian, further supporting their lethal-heat hypothesis.

Sun and co-authors suggest that the deadly warming was probably an after-effect

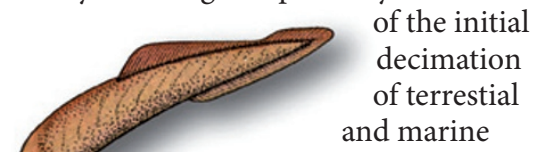
populations during the end-Permian extinction event. This first round of dying off crippled the land and marine plants' ability to draw down carbon dioxide, throwing the carbon cycle out of whack and causing prolonged heating as carbon dioxide accumulated in the atmosphere. As a result of this heating, more extinctions followed.

The work focuses on equatorial regions, but the authors expect that the basic patterns probably played out similarly at higher latitudes and hope to test this hypothesis. But all indicators from the work suggest that the authors have uncovered one of the most miserable and deadly time periods the planet has ever seen.

Mark Schrope is a freelance writer and editor based in Florida.

\section{The journalist's take}

A visit to the prehistoric world, even through brief glimpses, is an attractive opportunity for journalists. Modern humans love to think about strange-looking creatures navigating an effectively alien ocean. The finality of extinction also sparks a certain fascination, as does the solving of any manner of mystery.

But without the involvement of the words 'global' and 'warming', it is unlikely the paper would have received the global attention it did. The warming uncovered by the team took place on timescales of hundreds of thousands of years, and involved factors all but impossible to replicate in the modern world. So there is effectively no tie to the current global warming discussion. But readers and news editors probably still thought of the story as commenting in some way on a modern controversy.

The authors of the paper say that media articles have generally done a good job of describing their actual results, including making clear distinctions between modern and Triassic times. Part of the credit for this goes to the paper authors themselves: even though they (perhaps unnecessarily) started their main text with the words "anthropogenic global warming", they were careful to make the point that a repeat of the Smithian events would probably be impossible without mass destruction of our current vegetation, or a similar catastrophe.

Even most news headlines focused on the actual research, although a few did play on the modern climate change angle. National Geographic, for instance mentioning lethality and a planet devoid of life in an online article - asked, "Could it Happen Again?"

One aid to widespread coverage was the international team, which included scientists from China, Germany, Austria and the UK. Promotion by the Science press office was also a predictable boost. Other aspects of the coverage were not so predictable. The team was surprised to discover very strong interest from Iran, apparently due to mention of extreme heat in the Quran.

The relatively accurate reporting in the mainstream press was balanced by a blogosphere and article commenters at sites such as The Daily Mail, bent on creating and then critiquing a non-existent modern tie. Some accused the authors of being part of a conspiracy to create more fear about modern global warming. These commenters apparently missed the irony that a description of events 250 million years old with effectively no similarities with the present day would be poor propaganda indeed for modern climate discussions. 